\title{
Endoscopic transorbital superior eyelid approach: anatomical study from a neurosurgical perspective
}

\author{
Alberto Di Somma, MD, ${ }^{1}$ Norberto Andaluz, MD, ${ }^{2}$ Luigi Maria Cavallo, MD, PhD, ${ }^{1}$ \\ Matteo de Notaris, MD, PhD, ${ }^{3}$ lacopo Dallan, MD, ${ }^{4}$ Domenico Solari, MD, PhD, ${ }^{1}$ \\ Lee A. Zimmer, MD, PhD, ${ }^{5}$ Jeffrey T. Keller, PhD, ${ }^{2}$ Mario Zuccarello, MD, ${ }^{2}$ \\ Alberto Prats-Galino, MD, PhD, ${ }^{6}$ and Paolo Cappabianca, MD ${ }^{1}$
}

1Division of Neurosurgery, Department of Neurosciences and Reproductive and Odontostomatological Sciences, Università degli Studi di Napoli Federico II, Naples; ${ }^{3}$ Department of Neuroscience, G. Rummo Hospital, Neurosurgery Operative Unit, Benevento; ${ }^{4}$ First Otorhinolaryngologic Unit, Azienda Ospedaliero-Universitaria Pisana, Pisa, Italy; Departments of ${ }^{2}$ Neurosurgery and ${ }^{5}$ Otolaryngology-Head and Neck Surgery, University of Cincinnati College of Medicine, Comprehensive Stroke Center at UC Gardner Neuroscience Institute, Cincinnati, Ohio; and 'Laboratory of Surgical Neuroanatomy, Faculty of Medicine, Universitat de Barcelona, Barcelona, Spain

OBJECTIVE Recent studies have proposed the superior eyelid endoscopic transorbital approach as a new minimally invasive route to access orbital lesions, mostly in otolaryngology and maxillofacial surgeries. The authors undertook this anatomical study in order to contribute a neurosurgical perspective, exploring the anterior and middle cranial fossa areas through this purely endoscopic transorbital trajectory.

METHODS Anatomical dissections were performed in 10 human cadaveric heads ( 20 sides) using $0^{\circ}$ and $30^{\circ}$ endoscopes. A step-by-step description of the superior eyelid transorbital endoscopic route and surgically oriented classification are provided.

RESULTS The authors' cadaveric prosection of this approach defined 3 modular routes that could be combined. Two corridors using bone removal lateral to the superior and inferior orbital fissures exposed the middle and anterior cranial fossa (lateral orbital corridors to the anterior and middle cranial base) to unveil the temporal pole region, lateral wall of the cavernous sinus, middle cranial fossa floor, and frontobasal area (i.e., orbital and recti gyri of the frontal lobe). Combined, these 2 corridors exposed the lateral aspect of the lesser sphenoid wing with the Sylvian region (combined lateral orbital corridor to the anterior and middle cranial fossa, with lesser sphenoid wing removal). The medial corridor, with extension of bone removal medially to the superior and inferior orbital fissure, afforded exposure of the opticocarotid area (medial orbital corridor to the opticocarotid area).

CONCLUSIONS Along with its minimally invasive nature, the superior eyelid transorbital approach allows good visualization and manipulation of anatomical structures mainly located in the anterior and middle cranial fossae (i.e., lateral to the superior and inferior orbital fissures). The visualization and management of the opticocarotid region medial to the superior orbital fissure are more complex. Further studies are needed to prove clinical applications of this relatively novel surgical pathway.

https://thejns.org/doi/abs/10.3171/2017.4.JNS162749

KEY WORDS endoscopic keyhole; transorbital; eyelid approach; anatomy; surgical technique

$\mathrm{T}$ HE evolution of minimally invasive skull base approaches has accelerated dramatically as a result of refinement of microsurgical techniques and improvements in instrumentation, imaging, and surgical image guidance systems. Endoscopic endonasal techniques have served recently as a foundation and platform for the development of new strategies and the refinement of existing ones. ${ }^{39}$ For example, some midline ventral lesions of the anterior cranial fossa are now managed via the endoscopic endonasal route. In contrast, gold-standard open transcranial procedures, which generally achieve adequate surgical exposure for anterior and middle fossa patholo-

ABBREVIATIONS TONES = transorbital neuroendoscopic surgery.

SUBMITTED October 31, 2016. ACCEPTED April 14, 2017.

INCLUDE WHEN CITING Published online December 15, 2017; DOI: 10.3171/2017.4.JNS162749. 

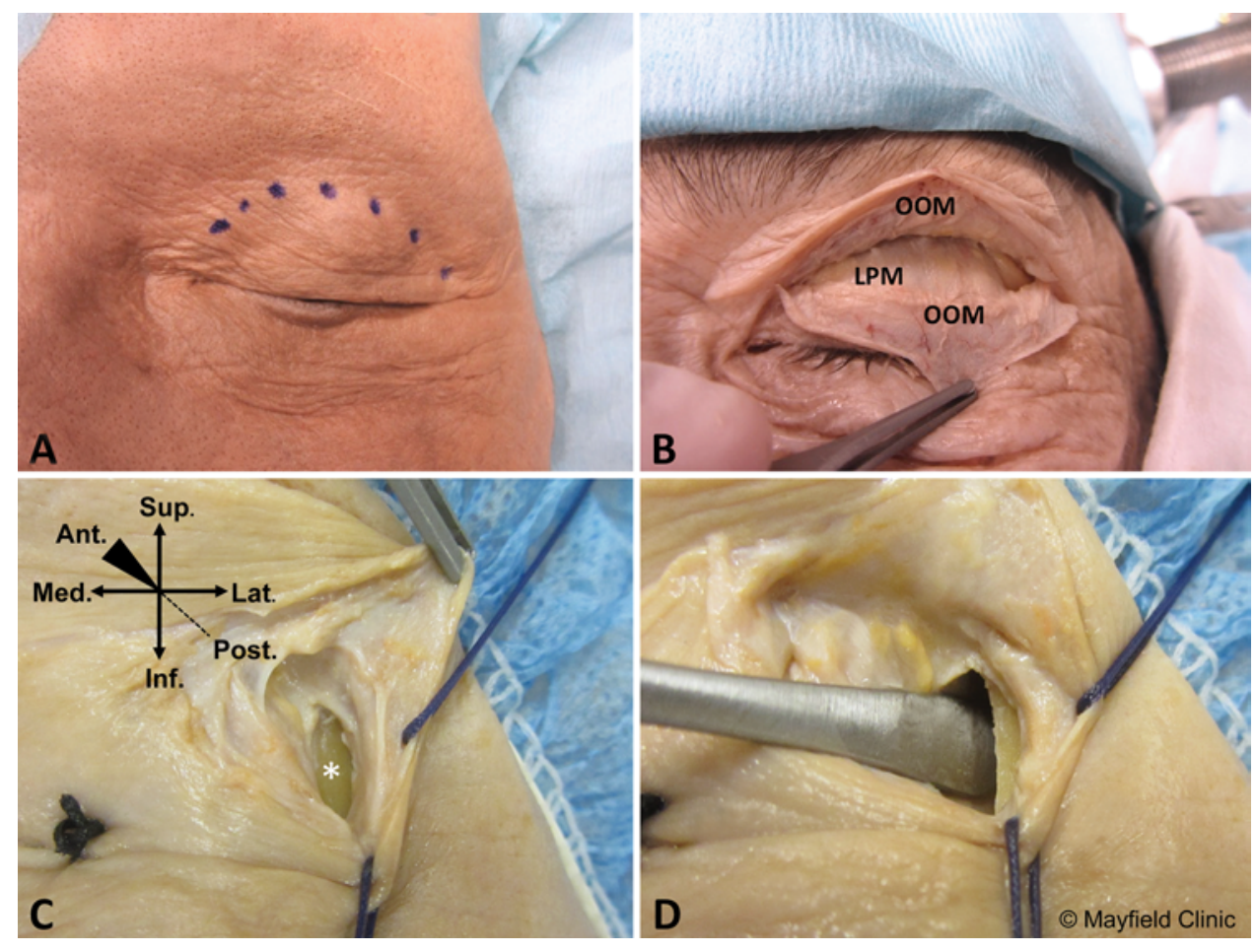

FIG. 1. Stepwise dissection of the superior eyelid endoscopic transorbital approach (left side). The head is slightly rotated to the contralateral side. After positioning, tarsorrhaphy is performed, and a skin incision is made in the crease of the superior eyelid ( $\mathbf{A}$, dotted line). The orbicularis oculi muscle (OOM) is separated in line with its fibers (B) to reach the frontal process of the zygoma, laterally $(\mathbf{C})$. The periosteum covering the zygoma is cut and dissected sharply toward the orbit where it becomes continuous with the periorbita (D). The asterisk $\left(^{*}\right)$ indicates the frontal process of the zygoma. Ant. = anterior; Inf. = inferior; Lat. = lateral; $L P M=$ levator palpebrae muscle aponeurosis; Med. = medial; Post = posterior; Sup. = superior. Printed with permission from Mayfield Clinic.

gies, can be associated with cosmetic and functional complications caused by the brain retraction needed to expose the skull base surface. $7,11,20,26,36,38,46,47$

Compared with open techniques, endoscopic and endoscope-assisted approaches can significantly reduce morbidity and achieve comparable outcomes in selected patients. ${ }^{4,22,25,31}$ In this context of endoscopic access, a potential alternative gateway to the skull base is the orbit. Indeed, a new group of surgical techniques that access the orbit and intracranial space has been recently referred to as transorbital neuroendoscopic surgery (TONES). ${ }^{35}$ One TONES corridor, the superior eyelid route, has proven to be clinically feasible as a route to selected anterior and middle skull base pathologies. ${ }^{6,32,35,39,40}$ However, the applicability and potential neurosurgical role of each transorbital corridor are not yet defined.

To this end, we provide a step-by-step cadaveric prosection using the superior eyelid endoscopic transorbital route and qualitatively assess its feasibility for selected skull base pathologies. We propose a surgically oriented classification based on extradural and intradural structures that can be exposed through these avenues. Specifically, our classification applies the most recent clinical applications of this minimally invasive pathway.

\section{Methods}

Ten adult cadaveric specimens (20 sides), without known intracerebral abnormality, were embalmed and injected with colored silicon rubber (Dow Corning) via the internal carotid arteries, vertebral arteries, and internal jugular veins. Before and after dissection, CT scans of the heads were performed, using $0.65-\mathrm{mm}$ cuts.

\section{Anatomical Dissections}

Anatomical dissections were performed at the University of Cincinnati Goodyear Microsurgery Laboratory and Laboratory of Surgical Neuroanatomy of the University of Barcelona (Spain). Dissections started macroscopically and then continued endoscopically. Endoscopic dissections were performed using a rigid 4-mm-diameter endoscope, $14 \mathrm{~cm}$ in length, with $0^{\circ}$ and $30^{\circ}$ rod lenses (Stryker) that were connected to a light source through a fiber optic canal and a video camera, which was connected to a video monitor; images were captured using a high-definition digital video system (Stryker). Specimens were positioned supine, pinned, and fixed in a Mayfield head holder, rotated $5^{\circ}$ laterally to the contralateral side (Fig. 1). A skin incision was placed in the superior eyelid crease, above the tarsal plate. A high-speed drill was used for bone removal.

After the orbicularis oculi muscle was opened in line with its fibers, dissection was performed in a superolateral direction up to the zygoma and frontozygomatic suture laterally. The periosteum was cut and dissected sharply 


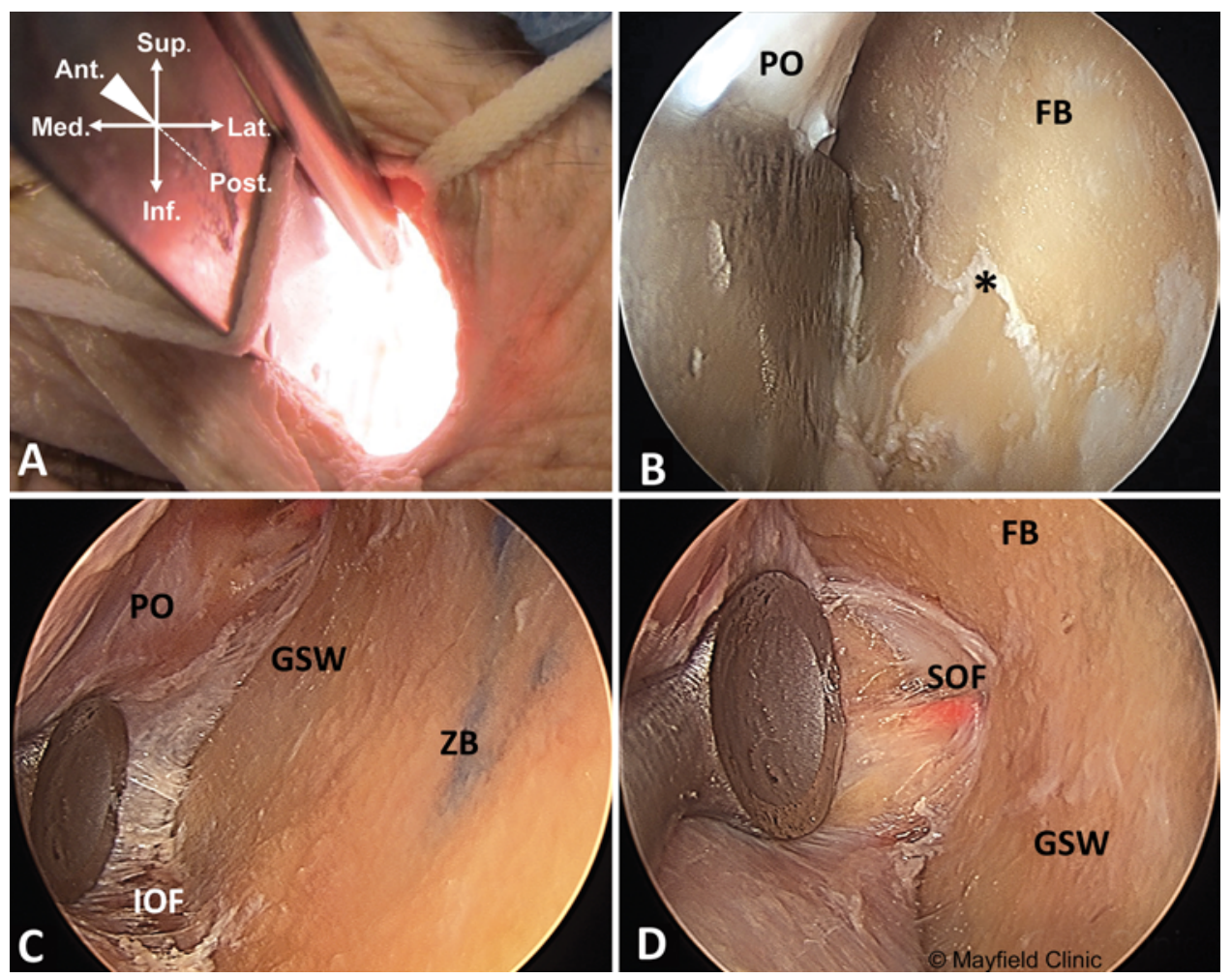

FIG. 2. Endoscopic transorbital access via the superior eyelid (left side). With the endoscope introduced in the upper portion of the orbit (A), subperiorbital dissection is performed following the frontozygomatic and frontosphenoidal sutures (B) until reaching the lateral end of the inferior (C) and superior orbital fissures (D). The asterisk $\left(^{*}\right)$ indicates the frontozygomatic and frontosphenoidal sutures. FB = frontal bone; GSW = greater sphenoid wing; IOF = inferior orbital fissure; $P O=$ periorbita; $S O F=$ superior orbital fissure; ZB = zygomatic bone. Printed with permission from Mayfield Clinic.

toward the orbit, where it becomes continuous with the periorbita. Using a No. 1 Penfield dissector, the surgeon followed the periosteum/periorbita plane within the orbit. Dissection proceeded along this plane until the lateral aspects of the inferior and superior orbital fissures were reached; this represented the limit to medial orbital content mobilization. Of note, near the superior orbital fissure, the cranio-orbital foramen (i.e., Hirtl's foramen) can be found; it usually accommodates the recurrent meningeal artery or the meningolacrimal branch (this vessel can pass even through the superior orbital fissure).,2, Placement of a malleable retractor separated the orbital contents medially from the posterolateral wall of the orbit, creating room for further dissection. The endoscope was then introduced in the upper portion of the surgical field to monitor the subsequent steps (Fig. 2).

In characterizing the exposure of intracranial neurovascular structures afforded by this purely endoscopic window, we defined a surgically oriented classification of the intracranial corridors that can be reached via this path -3 discrete corridors and 1 combined one (Fig. 3). This classification was based primarily on the position of the superior and inferior orbital fissures because they represent the early key anatomical and surgical landmarks of this route. Accordingly, the corridors were defined as follows: 1) lateral corridor to the middle cranial fossa; 2) lateral corridor to the anterior cranial fossa; 3 ) combined lateral corridor to the anterior and middle cranial fossa, with lesser sphenoid wing removal; and 4) medial corridor to the opticocarotid region.

Medial mobilization of the orbital contents, usually obtained during this kind of surgery, consisted of performing the lateral approaches to the anterior and middle cranial fossae (2 simple and 1 combined). Moreover, the removal of the most medial part of the lesser sphenoid wing, obtained after inferomedial mobilization of the orbital contents, provided additional surgical exposure with further exposition up to the opticocarotid region (Fig. 4). ${ }^{19}$

\section{Quantitative Statistical Analysis and 3D Reconstruction}

Following a complete transorbital approach, the area of exposure obtained for each region was calculated using the Brainlab cranial navigation system. For each of the 4 areas, 4 points were defined to represent the limits of bone removal.

For the middle fossa region, points included p1, maximal medial and lower extension toward the middle cranial base; p2, maximal lateral and lower extension toward the middle cranial base; $\mathrm{p} 3$, the superolateral edge of the superior orbital fissure; and p4, maximal lateral extension along the lesser sphenoid wing. For the anterior cranial fossa region, points included p1, maximal medial and higher extension toward the anterior cranial base; $\mathrm{p} 2$, maximal lateral and higher extension toward the anterior 

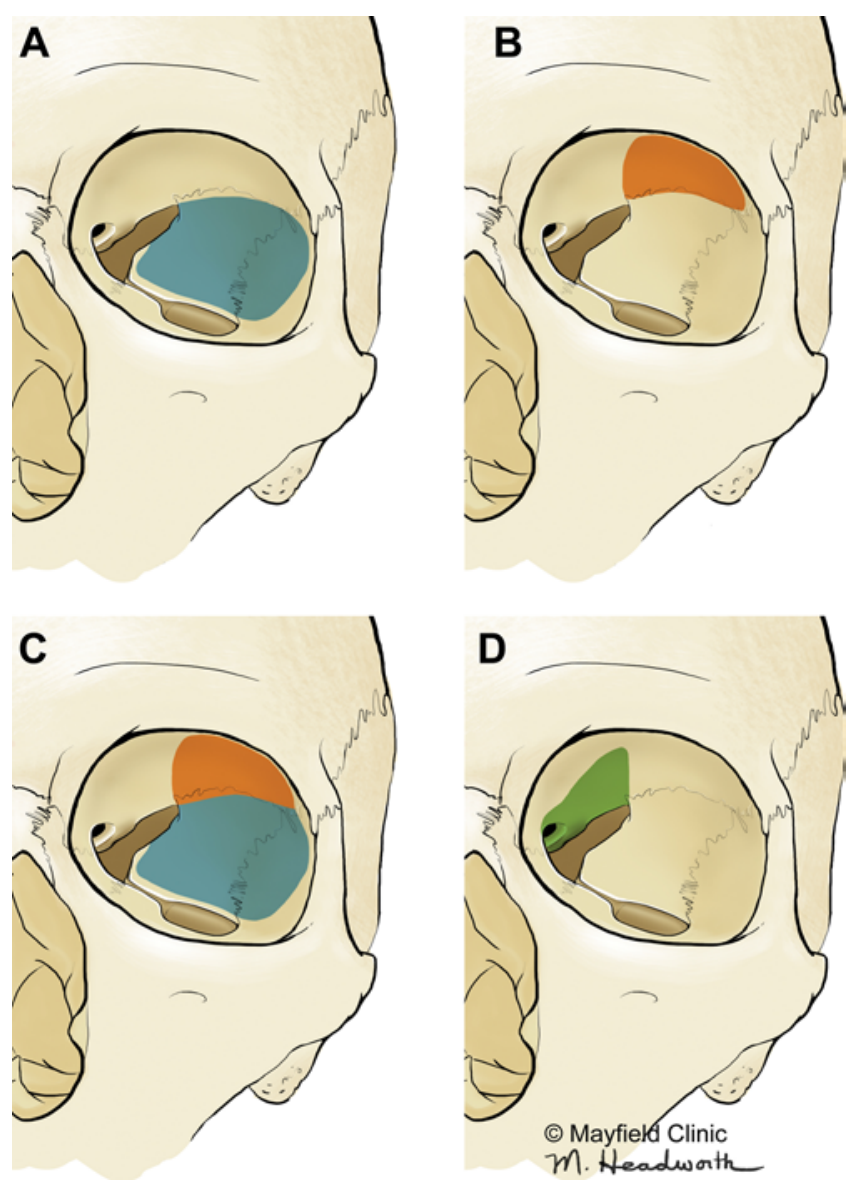

FIG. 3. Drawings (coronal view) of the left orbit showing 3 lateral corridors - 2 simple ( $\mathbf{A}$ and $\mathbf{B}$ ) and 1 combined $(\mathbf{C})$-and 1 medial corridor (D). Lateral approaches allow visualization of the anterior and middle cranial fossae; the medial corridor allows visualization of the opticocarotid region. Printed with permission from Mayfield Clinic.

cranial base; $\mathrm{p} 3$, corresponding to the superolateral edge of the superior orbital fissure; and p4, maximal lateral extension along the lesser sphenoid wing. The combined areas were calculated as the sum of anterior and middle fossa area exposures. The opticocarotid area was defined by merging these 3 points: 1 , the midportion of the optic canal; $\mathrm{p} 2$, superolateral edge of the superior orbital fissure; and p3, maximal medial and higher extension toward the anterior cranial base.

Cartesian coordinates of each point, obtained from the Brainlab workstation, yielded 3 vectors that were used to delineate 2 juxtaposed triangles. Areas of exposure were then calculated as the sum of the area of these 2 triangles; the opticocarotid area was represented by only 1 triangle.

A virtual 3D model of each area of exposure (Figs. 4 and 5) was created using Amira Visage Imaging software for visualization and manipulation of biomedical data. After bony structures were segmented from DICOM images using a semiautomatic threshold-based process, a smoothing feature was applied to further improve the rendering of the bony surfaces. The 3D reconstruction of the brain was obtained from a sample MRI study (Fig. 5).

All data were uploaded into Microsoft Excel, and an

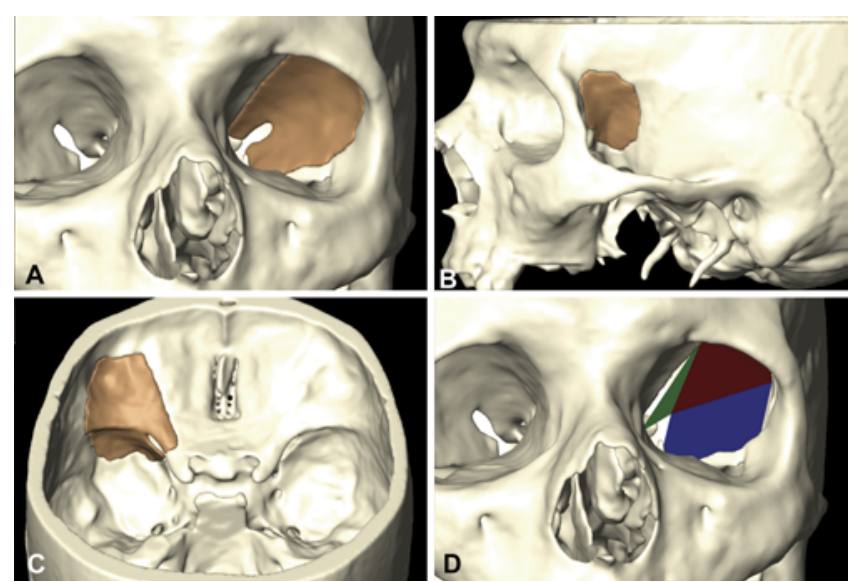

FIG. 4. A-C: 3D CT reconstructions showing bone removal via the endoscopic superior eyelid transorbital approach in coronal (A), sagittal (B), and axial (C) perspectives. D: 3D CT reconstruction showing the lateral and medial transorbital corridors. Blue indicates the middle fossa approach, red the anterior cranial fossa approach, and green the opticocarotid region. Figure prepared by the Laboratory of Surgical Neuroanatomy, University of Barcelona.

unpaired Student t-test was used to calculate statistical differences among the 4 modular approaches. A p value $<$ 0.01 was considered significant.

\section{Results}

In this step-by-step cadaveric prosection using the superior eyelid endoscopic transorbital route, our surgically oriented classifications defined 4 corridors based on the exposures of extradural and intradural structures (Table 1, Fig. 6). Our schematic classification defined the corresponding anatomical structures exposed, thus establishing possible surgical indications for each of these surgical modules and their eventual possible combinations. Consequently, 2 straightforward lateral corridors accessed the middle and anterior cranial fossae, respectively; a combined lateral corridor accessed both fossae by removal of the lesser sphenoid wing; and a medial corridor reached the opticocarotid region. Potential surgical indications for the superior eyelid endoscopic transorbital approach are summarized in Table 2.

\section{Lateral Orbital Corridor to the Middle Cranial Fossa}

The craniectomy, which was initially performed through the body of the zygoma to access the temporal fossa, was necessary to create adequate working room. The zygomatic body was drilled endo-orbitally without the necessity of removing the zygomatic arch, thus avoiding any cosmetic defect. Subsequently, the ventral and vertical portion of the greater sphenoid wing was drilled until the dura mater was exposed. This approach to the middle cranial fossa was bounded superomedially by the upper and lateral portion of the superior orbital fissure and the lateral part of the lesser sphenoid wing; laterally by the previously exposed periosteal surface of the temporalis muscle; inferomedially by the inferior orbital fissure; and inferiorly by the floor of the middle fossa. 


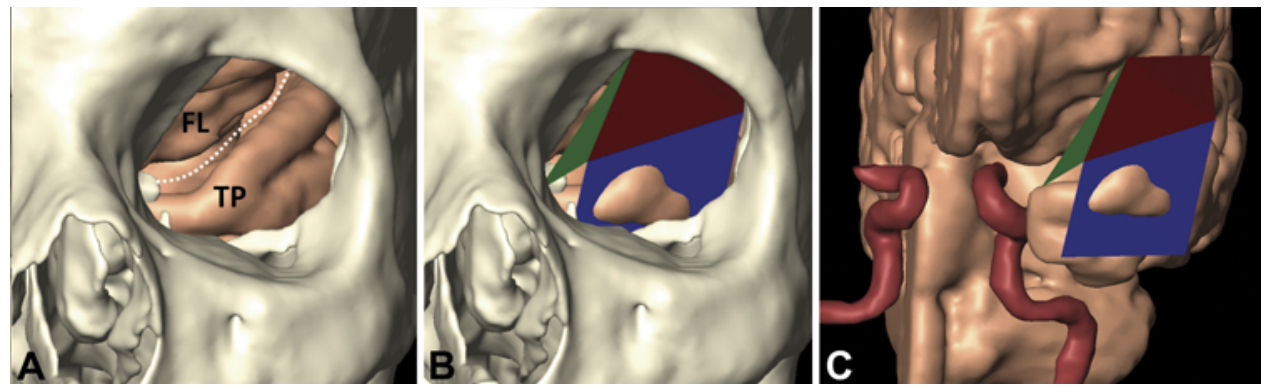

FIG. 5. 3D reconstructions obtained by merging the postdissection CT scan with a sample MR-based 3D reconstruction of the brain (made at the Laboratory of Surgical Neuroanatomy, University of Barcelona). A: Exposure of the temporal and frontal lobes seen via the transorbital route. The white dotted line indicates the Sylvian cistern. B and C: Lateral and medial areas with (B) and without $(C) 3 D$ reconstruction of bone removal. $\mathrm{FL}=$ frontal lobe; $\mathrm{TP}=$ temporal pole. Figure prepared by the Laboratory of Surgical Neuroanatomy, University of Barcelona.

Once the dura was exposed, an extradural dissection was performed in both lateral and inferior directions (Fig. 7). The inferior extradural dissection (i.e., toward the middle cranial fossa floor) was helpful in discovering the course of the middle meningeal artery as it emerged from the foramen spinosum. Moreover, medial extradural dissection was performed between the periorbita and the temporal pole. In this case, a complete extra/interdural visualization of the entire lateral wall of the cavernous sinus was achieved via the meningo-orbital band (Fig. 8). ${ }^{14}$ Subsequently, the dura mater was opened, exposing the temporal pole. The arterial and venous structures in this region can be closely seen at the center of the surgical field (Fig. 9).

\section{Lateral Orbital Corridor to the Anterior Cranial Fossa}

The craniectomy involved drilling the lateral basal frontal bone, corresponding to the orbital roof. The greater wing of the sphenoid can be left intact, whereas removal of the zygoma body must be adequate to gain appropriate space for dissection. The boundaries of this approach were delineated as follows: inferiorly, the lesser sphenoid wing; laterally, the pterion point as seen from the transorbital perspective; medially, the superior orbital fissure (i.e., its lateral aspect; medially and superiorly, the limit depended on the surgical target because it can potentially extend up to the posterior ethmoidal artery medially); and the orbital rim, superiorly.
After the craniectomy, extradural dissection allowed for exposure of the frontolateral convexity. Upon dural opening, the lateral and basal frontal lobe came into view. This portion of the frontal lobe corresponded to the orbital gyri, an irregular group of convolutions of the orbital surface. The orbital gyri were divided by the roughly $\mathrm{H}$ shaped orbital sulcus into the anterior, medial, posterior, and lateral orbital groups; from this perspective, the orbital sulcus can be well appreciated (Fig. 10). The anterior cranial fossa was also unlocked in its most medial portion. Accordingly, the frontal bone over this region, corresponding to the cribriform plate, was removed and an extradural exploration performed. Subsequently, the dura was opened to access the most medial portion of the basal frontal lobe, which in this case was represented by the gyrus rectus. Visualization of the frontomedial area with the aid of a $30^{\circ}$ endoscope allowed visualization of the olfactory nerve, just above the optic nerve, and the falx cerebri at the midline (Fig. 11).

\section{Combined Lateral Orbital Corridor to the Anterior and Middle Cranial Fossae, With Lesser Sphenoid Wing Removal}

The most lateral aspect of the lesser sphenoid wings lay in between the anterior and middle cranial fossae. Accordingly, the bone removal was extended so that this portion of the lesser sphenoid wing was totally removed extradurally, with the possibility for the resection to extend later-

TABLE 1. Extradural and intradural structures that can be exposed through different lateral and medial orbital corridors

\begin{tabular}{|c|c|c|}
\hline \multirow[b]{2}{*}{ Corridor } & \multicolumn{2}{|c|}{ Structures } \\
\hline & Extradural & Intradural \\
\hline Lateral corridor to MCF & $\begin{array}{l}\text { Temporalis muscle, pterion region, temporal pole } \\
\text { dura, recurrent meningeal artery, MMA, lateral wall } \\
\text { of cavernous sinus, middle cranial fossa floor }\end{array}$ & Temporal pole, MCF floor \\
\hline Lateral corridor to ACF & Frontolateral basal dura, frontomedial basal dura & Orbital gyri, gyri recti, olfactory nerve, falx cerebri \\
\hline Combined lateral corridor to ACF \& MCF & Lesser sphenoid wing, pterion region & Sylvian fissure, MCA \& its branches \\
\hline Medial corridor to OCR & $\begin{array}{l}\text { Posterior ethmoidal artery, anterior clinoid process, } \\
\text { optic nerve }\end{array}$ & $\begin{array}{l}\text { Optic nerve, optic chiasm, ICA, oculomotor nerve, } \\
\text { pituitary stalk }\end{array}$ \\
\hline
\end{tabular}

$\mathrm{ACF}=$ anterior cranial fossa; $\mathrm{ICA}=$ internal carotid artery; $\mathrm{MCA}=$ middle cerebral artery; $\mathrm{MCF}=$ middle cranial fossa; $\mathrm{MMA}=$ middle meningeal artery; $\mathrm{OCR}=\mathrm{opticoca}-$ rotid region. 


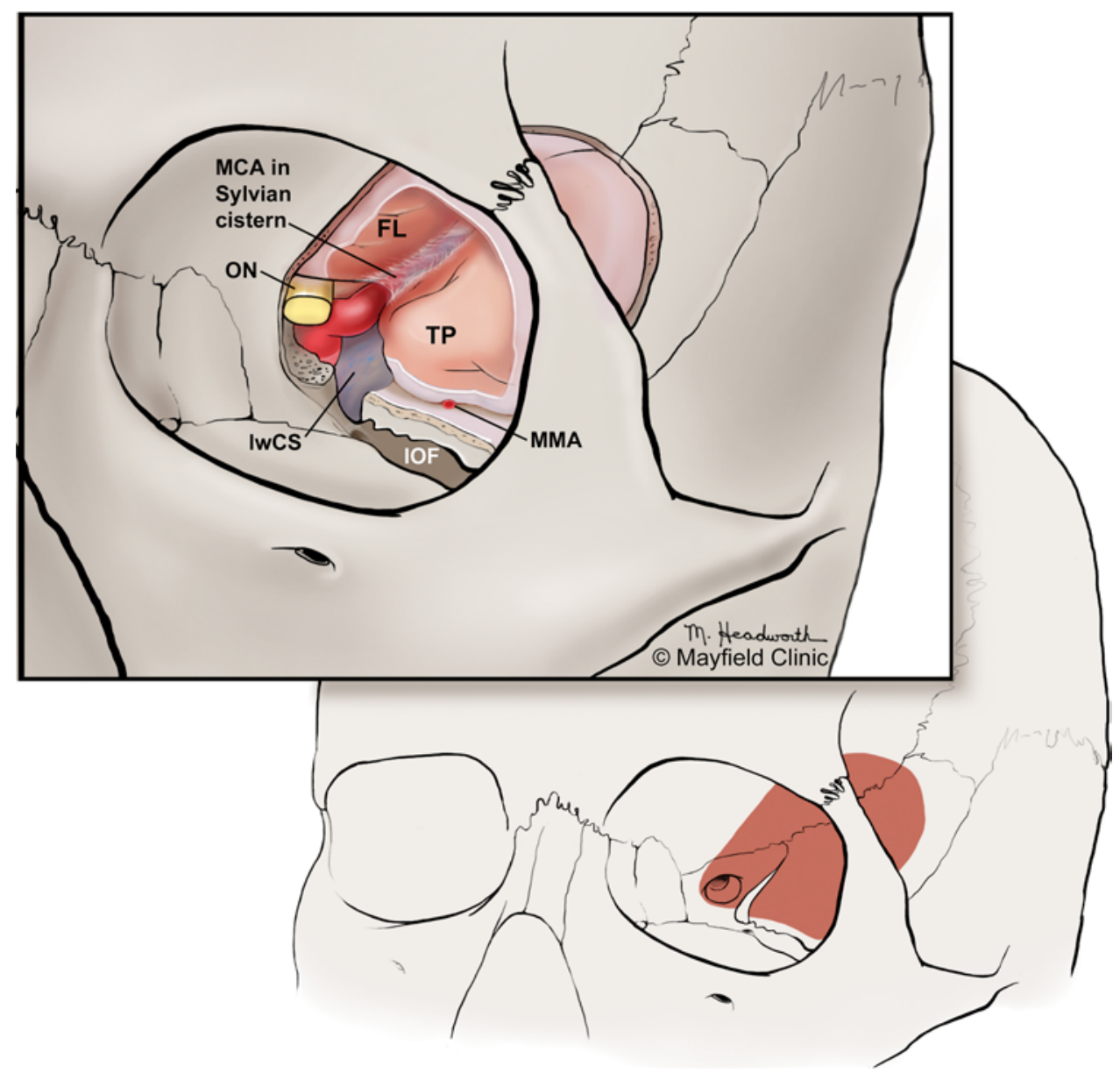

FIG. 6. Artistic illustration depicting the main neurovascular structures seen via the transorbital window. IwCS = lateral wall of the cavernous sinus; $\mathrm{MCA}=$ middle cerebral artery; $\mathrm{MMA}=$ middle meningeal artery; $\mathrm{ON}=$ optic nerve. Printed with permission from Mayfield Clinic.

ally up to the pterion. In fact, this procedure allowed good visualization of the pterional area as seen from inside the orbit: a visualization totally different and opposite from standard transcranial procedures (e.g., pterional route).
After dural opening, the most anterior portion of the sylvian fissure, with its cistern, was visualized. The middle cerebral artery and its branches were exposed using sharp dissection (Fig. 12).

TABLE 2. Potential indications for the transorbital approach, based on each area

\begin{tabular}{|c|c|c|c|c|}
\hline \multirow[b]{2}{*}{ Approach } & \multicolumn{4}{|c|}{ Indication } \\
\hline & Primary Brain Tumors & Primary Bone Diseases & Vascular Diseases & Other \\
\hline $\begin{array}{l}\text { Middle cranial } \\
\text { base }\end{array}$ & $\begin{array}{l}\text { Selected spheno-orbital menin- } \\
\text { giomas, lesions at lateral wall } \\
\text { of cavernous sinus, biopsy for } \\
\text { temporal pole gliomas }\end{array}$ & $\begin{array}{l}\text { Osteoma, Paget, Crou- } \\
\text { zon, fibrous dysplasia }\end{array}$ & $\begin{array}{l}\text { AVMs or other vascular anomalies } \\
\text { at temporal pole, vascular anom- } \\
\text { alies at lateral wall of cavernous } \\
\text { sinus (cavernous hemangioma) }\end{array}$ & $\begin{array}{l}\text { Amygdalohippocampec- } \\
\text { tomy, other functional } \\
\text { neurosurgical proce- } \\
\text { dures }\end{array}$ \\
\hline $\begin{array}{l}\text { Anterior cranial } \\
\text { base }\end{array}$ & $\begin{array}{l}\text { Selected spheno-orbital menin- } \\
\text { gioma, biopsy for fronto-basal } \\
\text { gliomas }\end{array}$ & $\begin{array}{l}\text { Osteoma, Paget, Crou- } \\
\text { zon, fibrous dysplasia }\end{array}$ & $\begin{array}{l}\text { AVMs or other vascular anomalies } \\
\text { at lateral frontobasal lobe }\end{array}$ & $\begin{array}{l}\text { Functional neurosurgical } \\
\text { procedures }\end{array}$ \\
\hline $\begin{array}{l}\text { Combined anterior } \\
\text { \& middle fossa }\end{array}$ & $\begin{array}{l}\text { Selected spheno-orbital menin- } \\
\text { giomas }\end{array}$ & $\begin{array}{l}\text { Osteoma, Paget, Crou- } \\
\text { zon, fibrous dysplasia }\end{array}$ & MCA aneurysms & $\begin{array}{l}\text { Complex CSF leaks, menin- } \\
\text { goencephalocele }\end{array}$ \\
\hline $\begin{array}{l}\text { Opticocarotid } \\
\text { region }\end{array}$ & $\begin{array}{l}\text { Optic nerve sheath meningio- } \\
\text { mas, optic nerve biopsy }\end{array}$ & $\begin{array}{l}\text { Osteoma, Paget, Crou- } \\
\text { zon, fibrous dysplasia }\end{array}$ & & $\begin{array}{l}\text { Foreign body or fracture at } \\
\text { lateral side of optic canal }\end{array}$ \\
\hline
\end{tabular}

$\mathrm{AVM}=$ arteriovenous malformation; $\mathrm{DBS}=$ deep brain stimulation . 

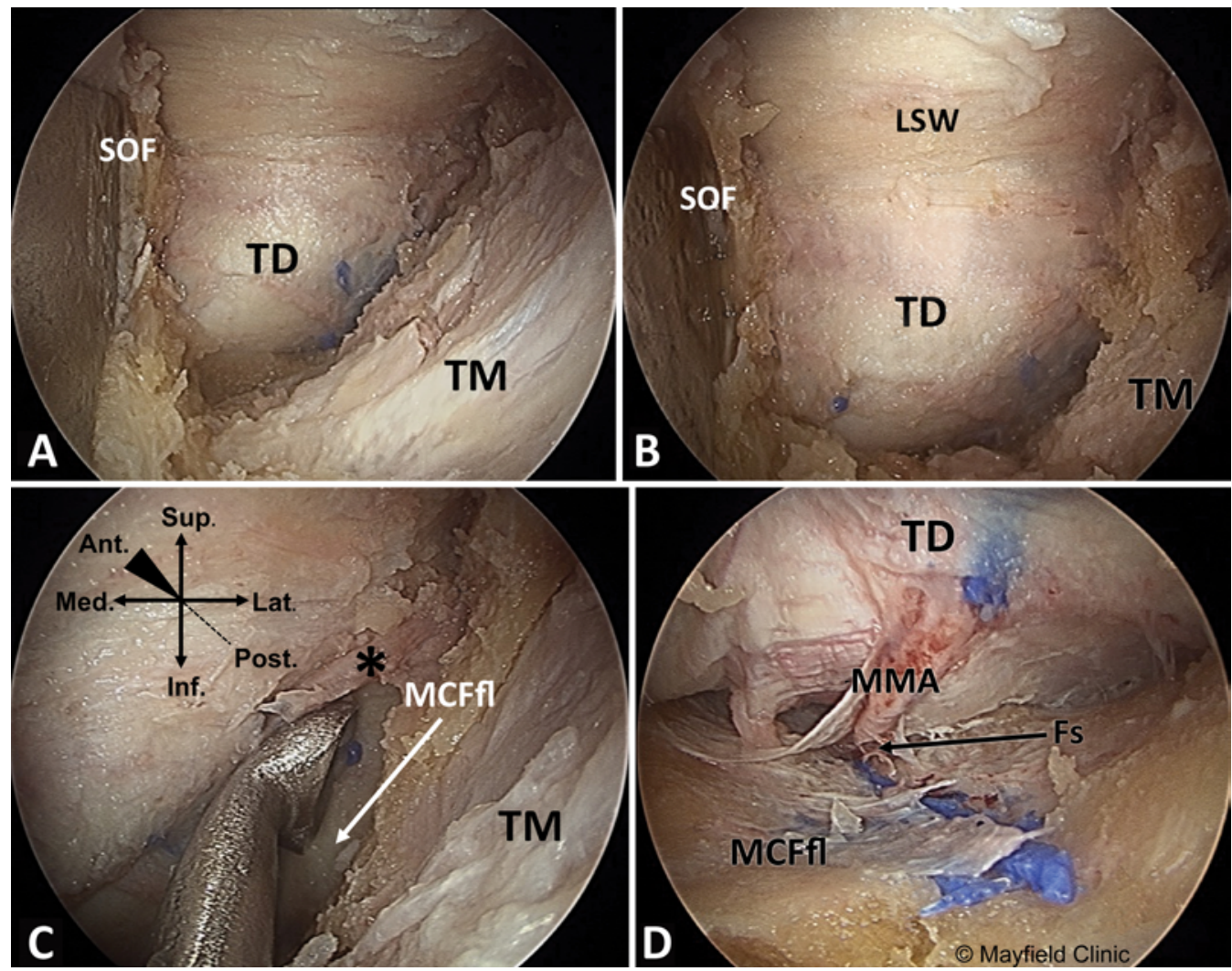

FIG. 7. Lateral orbital corridor to the middle cranial fossa. Body of the zygoma and greater sphenoid wing drilled up to the lateral end of the superior orbital fissure. The temporalis fossa, containing the temporalis muscle covered by its fascia, is first unlocked to gain room (A). The dura mater of the middle cranial fossa (MCF) is exposed (B). Dissection can proceed laterally and inferiorly in an extradural fashion; thus the most lateral part of the MCF can be exposed near the pterion point. With use of this pathway in an inferior direction, the entire MCF floor (MCFfl) can be evaluated (C) while the middle meningeal artery (MMA) can be followed, entering into the foramen spinosum (Fs) (D). The asterisk $\left(^{*}\right)$ indicates the recurrent meningeal artery. LSW = lesser sphenoid wing; TD = temporal pole dura; TM = temporal muscle, covered by its fascia. Printed with permission from Mayfield Clinic.

\section{Medial Orbital Corridor to the Opticocarotid Area}

The dissection described above was continued in a medial direction up to the most medial portion of the lesser sphenoid wing. The opticocarotid region can be reached by extending the bone removal superiorly and medially to the superior orbital fissure-that is, after mobilization of the orbital contents inferomedially. This area was limited by the superior orbital fissure laterally, the posterior ethmoidal artery medially, the floor of the optic canal and the optic strut inferiorly, and the frontosphenoidal suture superiorly. The posterior ethmoidal artery should be cut to facilitate mobilization of the orbital contents and thus better expose this region. With the optic canal opened in its superior and lateral part, the optic nerve was followed in its intracranial segment where it joined the contralateral optic nerve to form the optic chiasm. Intracranial exploration of this area allowed visualization of the opticocarotid region from a ventral perspective, including the internal carotid artery bifurcation, opticocarotid cistern, and the third cranial nerve.

With the aid of a $30^{\circ}$ endoscope and after opening of the opticocarotid cistern, the pituitary stalk, surrounded by the diaphragma sellae, was appreciated in the subchiasmatic space (Fig. 13). Of note, although this area was reached in anatomical specimens, its surgical exposure may be difficult in the clinical setting, unless there is a specific space-occupying lesion.

\section{Quantitative Analysis}

In quantifying the extent of bone removal for each area, we found the middle and anterior fossa approaches achieved a greater amount of bone removal than the opticocarotid region approach (Table 3, Figs. 4 and 5). When compared with the middle fossa and opticocarotid region approaches, the anterior cranial base approach yielded greater bone removal. Obviously, the combined approach achieved the greatest bone removal. Statistical significance, calculated with an unpaired Student t-test, was defined as $\mathrm{p}<0.01$. However, the t-value was quite low, and the difference in bone removal between anterior cranial base and middle fossa approaches was small (Table 3, Fig. 14).

\section{Discussion}

As the new group of transorbital neuroendoscopic surgery procedures (TONES) emerged, the superior eyelid route represented a clinically feasible corridor to selected anterior and middle skull base pathologies. With the 

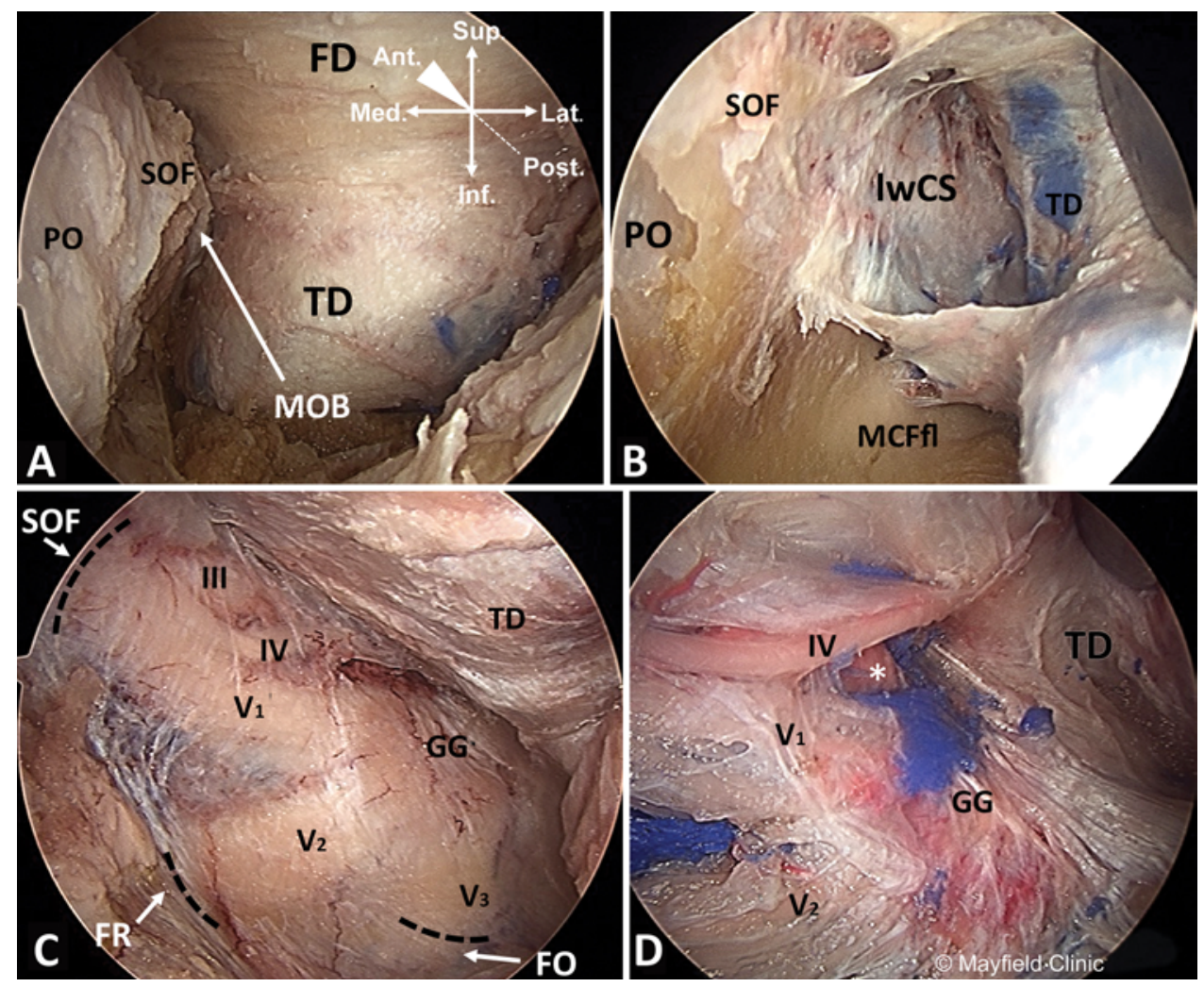

FIG. 8. Extradural medial exposure of the periorbita-temporal pole interface (A). Dissection between the periorbita and temporal pole, inferior to the superior orbital fissure (i.e., at the level of the meningo-orbital band) (B). Lateral wall of the cavernous sinus (C) and intracavernous carotid artery $\left(^{*}\right)(\mathrm{D})$ exposed. $\mathrm{FO}=$ foramen ovale; FR = foramen rotundum; GG = gasserian ganglion; MCFfl = middle cranial fossa floor; $\mathrm{MOB}=$ meningo-orbital band; III = CN III (oculomotor nerve); IV = CN IV (trochlear nerve); V1 = ophthalmic branch of CN V (trigeminal nerve); V2 = maxillary branch of CN V; V3 = mandibular branch of CN V. Printed with permission from Mayfield Clinic.

applicability and potential neurosurgical role of various transorbital corridors yet to be established, our cadaveric prosection defined, in a stepwise fashion, 3 modular routes and qualitatively assessed their feasibility for selected skull base pathologies. As a result, our proposed classi- fications are surgically oriented based on the extradural and intradural structures exposed through this avenue and based on the most recent clinical applications of this minimally invasive pathway. The superior eyelid endoscopic transorbital approach can yield good visualization of the

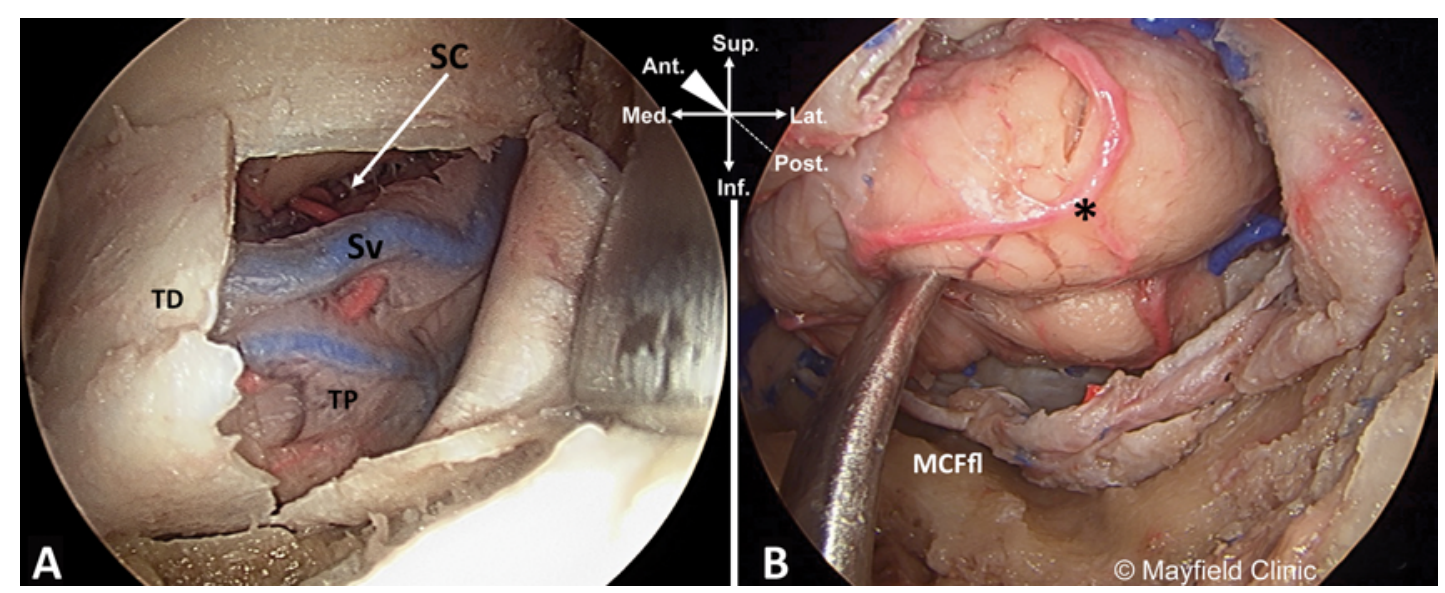

FIG. 9. Intradural exploration of the middle cranial fossa. After dura opening, temporal pole came into view. The asterisk (*) indicates the temporal cortical branches of the middle cerebral artery. SC = Sylvian cistern; Sv = Sylvian vein; TP = temporal pole, covering by the arachnoid. Printed with permission from Mayfield Clinic. 


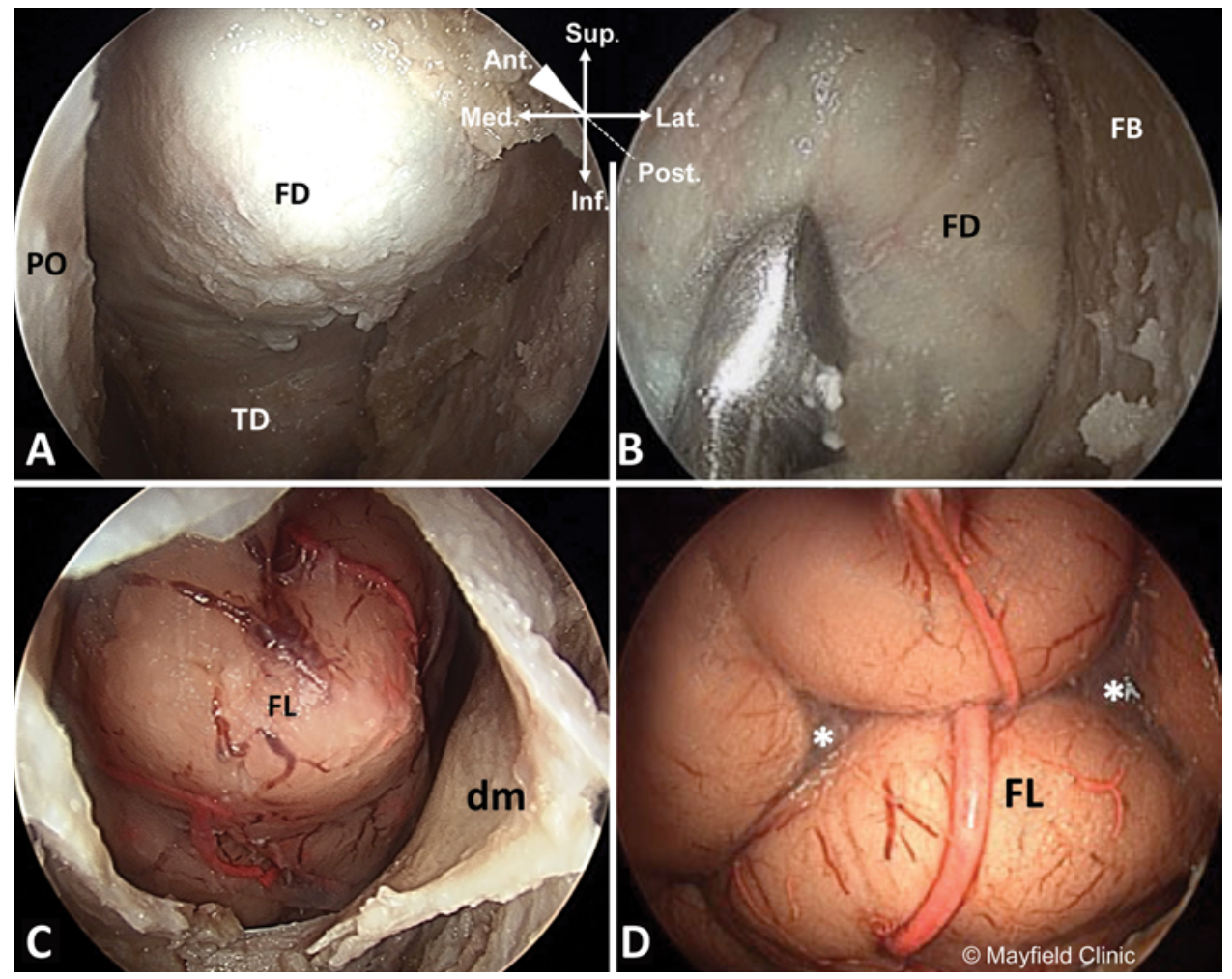

FIG. 10. Lateral orbital corridor to the anterior cranial fossa. With removal of the basal frontal bone medial to the superior orbital fissure and superior to the lesser sphenoid wing, the dura covering the frontal lobe (FL) came into view (A). Dissection can proceed laterally in extradural fashion (B). Opening of the dura mater $(\mathrm{dm})$ then allows intradural exploration of the basal frontal lobe (C); the $\mathrm{H}$-shaped orbital sulcus can be appreciated (D). The asterisks $\left(^{*}\right)$ indicate cortical arterial branches of the frontal lobe. Printed with permission from Mayfield Clinic.

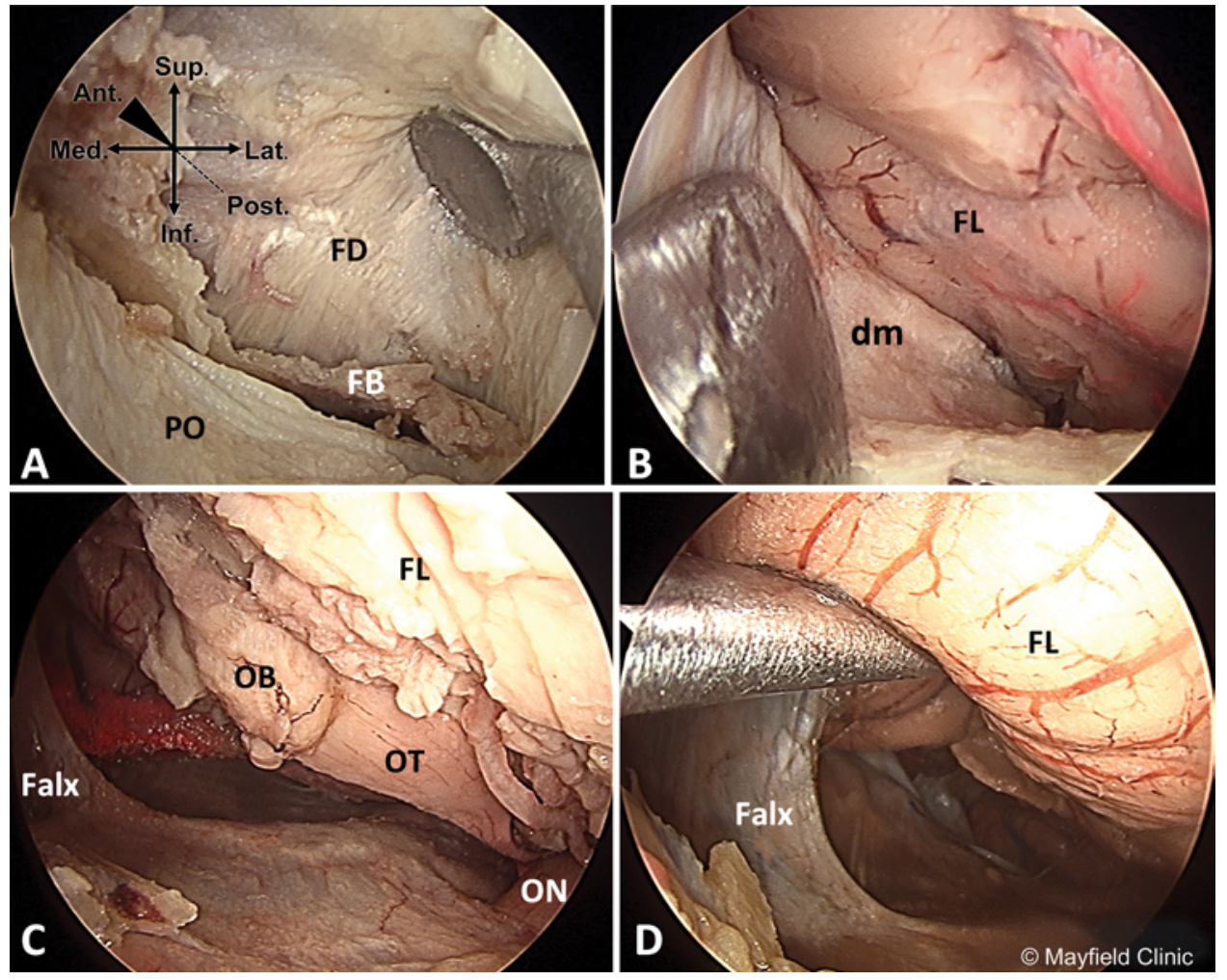

FIG. 11. Views obtained with a $30^{\circ}$ endoscope, showing further exposure of the anterior cranial fossa via the lateral orbital corridor. Even with the $30^{\circ}$ endoscope, the area can be explored extradurally $(\mathbf{A})$ and intradurally $(\mathrm{B}-\mathrm{D})$. Falx $=$ falx cerebri; $\mathrm{OB}=$ olfactory bulb; OT = olfactory tract. Printed with permission from Mayfield Clinic. 


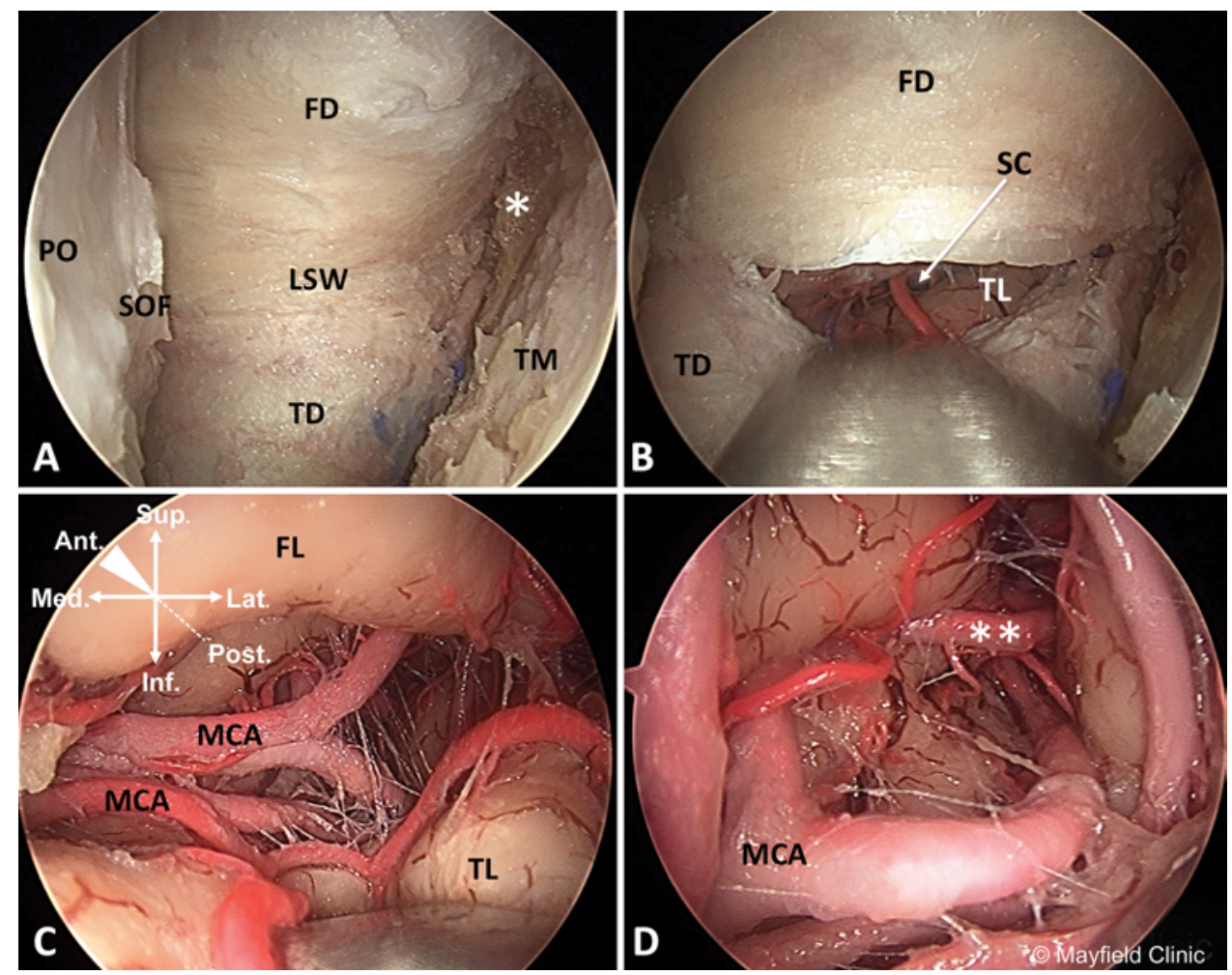

FIG. 12. Combined lateral approach to the anterior and middle cranial fossa. Close-up view showing lesser sphenoid wing (LSW) dividing the anterior and middle cranial fossae (A). The dura is cut between the anterior and middle cranial fossae at the level of the LSW to reach the intracranial space (B). The main course of the middle cerebral artery (MCA) can be appreciated (C and D). The asterisk $\left(^{*}\right)$ indicates the pterion seen through the transorbital perspective; the double asterisks $\left(^{* *}\right)$ indicate insular branches of the MCA. TD = temporal dura; $T L=$ temporal lobe. Printed with permission from Mayfield Clinic.

basal anterior fossa and anteromedial middle fossa. Using the endoscopic microsurgical technique, surgical manipulation of structures in the anterior and middle cranial fossae is feasible. Lateral orbital corridors to the superior and inferior orbital fissures exposed the entire rostral middle fossa and the anterior cranial fossa laterally to the convexity. Additional bone removal medial to the superior and inferior orbital fissures defined a medial transorbital corridor to the opticocarotid region.

\section{Evolution of the Transorbital Path}

The transorbital pathway has been used intermittently in neurosurgery for at least 60 years. In 1948, the American physician Walter J. Freeman II popularized the transorbital leucotomy ${ }^{24}$ based on a technique developed by the Italian psychiatrist Amarro Fiamberti. ${ }^{23}$ This "minimal invasive" transorbital procedure soon became ubiquitous across the landscape of psychiatric care in the United States and many parts of Europe. Subsequently, the social and ethical implications of widespread overuse of transorbital lobotomies drove this procedure to near extinction. ${ }^{40}$ Several other approaches were reported based on the ventral transorbital route, including intraventricular procedures, ${ }^{34,47-49}$ decompression for orbital and Graves' disease, ${ }^{1,3,33}$ and experimental and diagnostic vascular applications. . $2,17,27,28,37$ Thereafter, targets such as the cavernous sinus, ${ }^{6,16,41}$ pituitary stalk, ${ }^{42}$ and optic nerve ${ }^{29,45}$ were considered reachable via this minimally invasive avenue for various diagnostic, experimental, and/or therapeutic purposes.

During the past 2 decades, improvements in endoscope optics quality, materials, instrumentation, and surgical navigation systems have advanced the development of modern skull base surgery. The collaboration of otolaryngologists and neurosurgeons for the treatment of pathologies that were beyond the reach of each other's specialties invited a new subspecialty called endoneurosurgery, with its route based mainly on the endonasal corridor. ${ }^{8}$

Despite these impressive developments, nasal anatomy and geometrical relations to the skull base often limit working angles and visualization of certain structures, particularly for lesions that cross neurovascular structures or are situated in far-lateral areas. ${ }^{44}$ In such cases, decreased visualization can lead either to complications or to incomplete surgery. In contrast, traditional external skull base approaches offer wide exposure and control of lesions, but sometimes at the expense of increased brain exposure and retraction, thus leading to postoperative functional and cosmetic sequelae., $711,20,26,36,38,46,47$

In this context, craniofacial anatomy studies suggested that the orbits, if crossed safely, can provide access to those areas of the anterior and middle skull base that are not safely accessed endonasally. That is, the obstacle represented by the carotid arteries and cranial nerves in the 


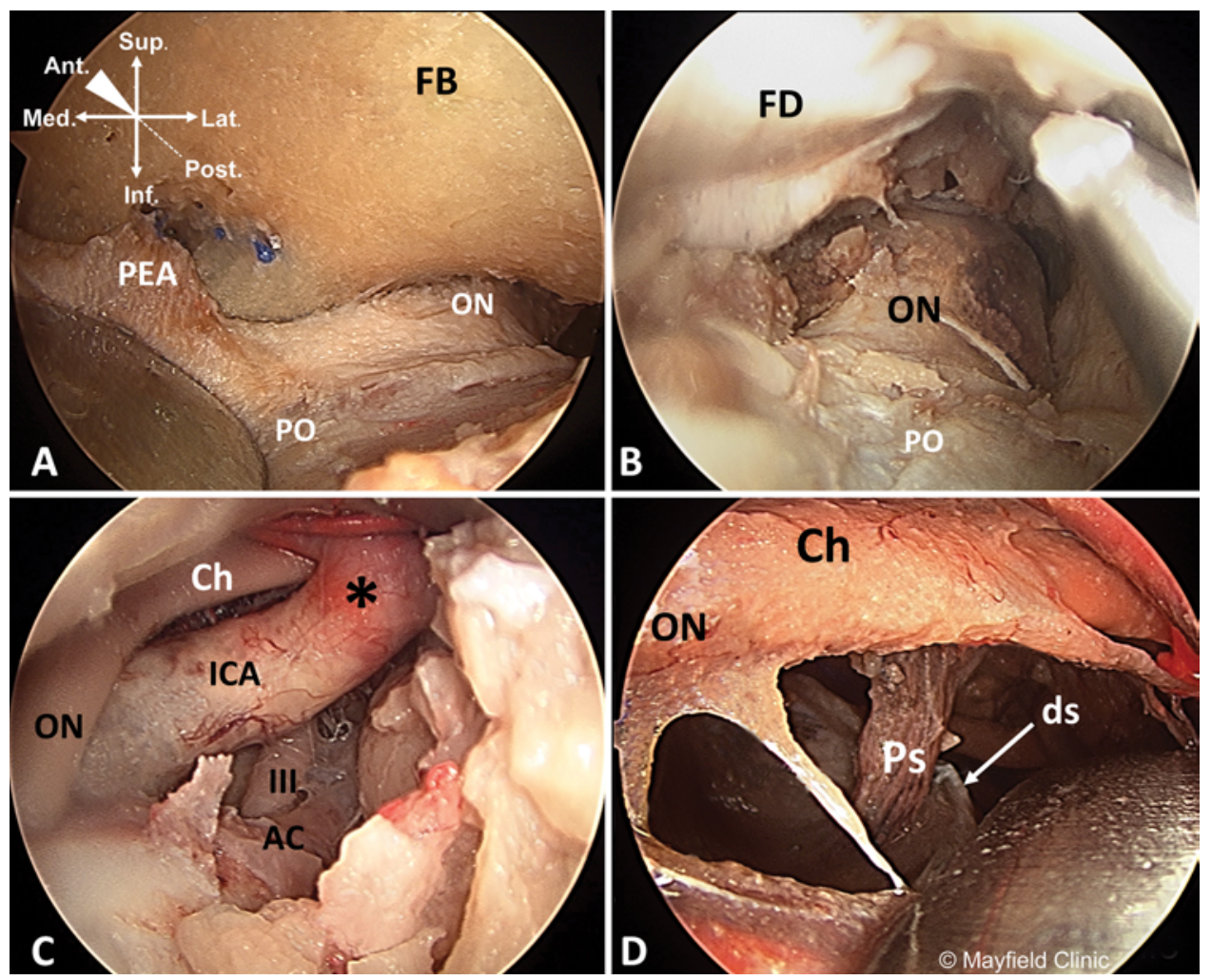

FIG. 13. Medial orbital corridor to the opticocarotid area (left orbit) (A). The optic nerve can be followed from its intracanalicular portion (B) up to the intracranial segment, where it lies close to the internal carotid artery (ICA) (C). With aid of a $30^{\circ}$ lens, the subchiasmatic region can be explored through this window. The asterisk $\left(^{*}\right)$ indicates the ICA bifurcation. AC = anterior clinoid process; $\mathrm{Ch}=$ chiasm; $d s=$ diaphragma sellae; $\mathrm{PEA}=$ posterior ethmoidal artery; $\mathrm{Ps}=$ pituitary stalk. Printed with permission from Mayfield Clinic.

lateral extension of endonasal approaches can be overcome by accessing the areas lateral to those anatomical hurdles. Consequently, the addition of transorbital approaches presented a complementary resource to endonasal approaches for the treatment of lesions that involve the neurovascular structures, a concept recently introduced as "multiportal endoneurosurgery." ${ }^{, 5,8,10,18,43}$

\section{Transorbital Neuroendoscopic Surgery}

Access to the anterior skull base through the orbit with endoscopic assistance is not a new concept. The concept presented as "transorbital neuroendoscopic surgery (TONES)" ",32,35,39 described a group of endoscopic surgical pathways, a system of orbitotomies that could be indicated for various pathologies that affect the anterior and middle fossae. Truly transorbital, these procedures do not require removal of the orbital rim or frontal bone convexity. Their novel, attractive routes offer minimal morbidity, no visible scars, small craniotomy size, minimal brain retraction, and in some cases, coplanar path-to-target dissection. As a result, collateral damage to adjacent neurological and vascular structures is held to a minimum, patient recovery is rapid, and intensive care unit stays can be reduced or avoided. 6,32,35,39,49

One TONES corridor is the superior eyelid route, proven in clinical settings as a possible way to select mainly laterally placed anterior and middle skull base targets. ${ }^{30}$ Its superior eyelid skin incision offers the advantage of being hidden when the patient's eyes are open, provides dissection in natural anatomical planes, and affords preservation of the temporalis muscle, thus facilitating an acceptable cosmetic outcome, as described in initial surgical experiences and anatomical reports. ${ }^{2,9,13,15}$ With no dedicated

TABLE 3. Quantitative analysis of bone removal obtained with the endoscopic superior eyelid approach

\begin{tabular}{lcccc}
\hline Analysis for Bone Removal & Area $\left(\mathrm{mm}^{2}\right)^{*}$ & $\mathrm{t}$ Value† & DF & $\mathrm{p}$ Value \\
\hline MCF & $490.24 \pm 76.94$ & - & - & - \\
\hline ACF & $620.47 \pm 73.46$ & - & - & - \\
\hline Combined lateral approach & $1110.71 \pm 131.89$ & - & - & - \\
\hline OCR & $115.41 \pm 52.43$ & - & - & - \\
\hline MCF vs ACF & - & 3.87 & 18 & $<0.01$ \\
\hline MCF vs combined lateral & - & 12.85 & 18 & $<0.01$ \\
\hline MCF vs OCR & - & 12.73 & 18 & $<0.01$ \\
\hline ACF vs combined lateral & - & 6.61 & 18 & $<0.01$ \\
\hline ACF vs OCR & - & 17.70 & 18 & $<0.01$ \\
\hline Combined lateral vs OCR & - & 16.87 & 18 & $<0.01$ \\
\hline DF $=$ degrees of freedom. & & & & \\
* Mean \pm SD. \\
$\dagger$ Student t-test.
\end{tabular}




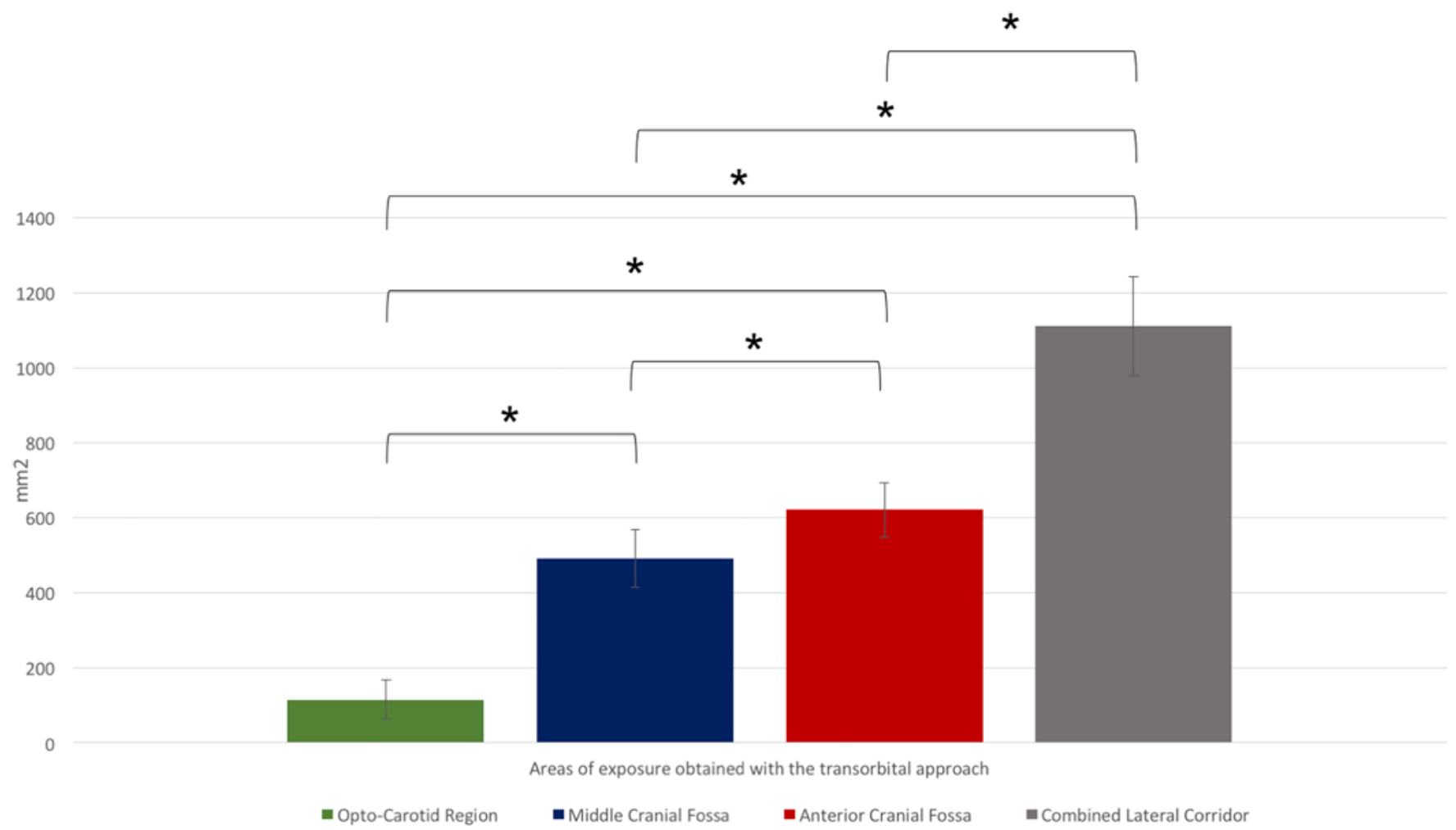

FIG. 14. Areas of exposure obtained with the endoscopic superior eyelid transorbital approach. Corridors represented included the lateral orbital corridor to the middle cranial base (blue); the lateral orbital corridor to the anterior cranial base (red); the combined lateral orbital corridor to the anterior and middle cranial fossae (gray); and the medial orbital corridor to the opticocarotid area (green). Compared with opticocarotid region approach, the middle and anterior fossa approaches achieved greater bone removal. Compared with middle fossa and opticocarotid region approaches, the anterior cranial base approach had greater bone removal, and the combined approach had the greatest bone removal of all. ${ }^{*} p<0.01$ (unpaired t-Student test).

study that addressed a schematic classification of the intracranial structures approached via this novel route, we undertook the anatomical analysis presented in this paper in order to determine the applicability of the various transorbital routes to the neurosurgical pathologies of the anterior and middle cranial fossae.

Using anatomical landmarks in relation to the orbital contents, we built a modular approach that was defined by discrete corridors and further separated these into lateral (i.e., lateral to the superior and inferior orbital fissures) and medial (i.e., extension medial to the superior and inferior orbital fissures) corridors. Based on our observations, we defined 3 lateral corridors ( 2 simple and 1 combined) and 1 medial corridor. The lateral corridors permitted exposure of the most lateral portion of the middle or anterior cranial fossa whereas the medial corridor, which included further bone removal medially to the superior and inferior orbital fissures, extended to reach the opticocarotid area. We concluded that the first 3 approaches (i.e., the 2 discrete lateral approaches and their combination) achieved better surgical exposures than the medial one, related to the opticocarotid region. Nonetheless, maneuverability was closely related to globe compliance and variability of the specimens for anatomical dissections.

Future applications of this minimally invasive, purely endoscopic route may include resection of tumors that ex- tend in the parasellar region or other tumors (e.g., spheno-orbital meningiomas and selected anterior and middle skull base meningiomas). With increased experience and improved instrumentation and repair techniques, the treatment of selected skull base pathologies could be possible though these approaches. ${ }^{7,17,37}$

The purely endoscopic, superior eyelid, transorbital approach to the anterior and middle cranial base represents an additional avenue in the evolving discipline of minimally invasive skull base surgery or a possible alternative and/or adjunct to transcranial approaches for pathologies of the rostral anterior and middle fossae. ${ }^{48,49}$ Combining transnasal and transorbital ports, surgeons can optimize visualization, choose the trajectory and working distance, and maximize the working space between their hands and instruments. $^{13}$

In selected clinical situations, this technique has been reported as safe, offers better access and visualization than open or transnasal approaches, and retains the benefits of minimally disruptive surgery. Further comparative anatomical analyses, mandatory to understand pros and cons of a new technique, are ongoing to help understand the specifics of each route.

\section{Limitations}

In this study, one limitation was our use of cadaveric 
specimens, which, though useful models to investigate surgical approaches, cannot fully replicate the clinical environment. Tissue characteristics, bleeding, and the tolerable amount of globe retraction must be taken into consideration. Continuous intraoperative globe tonometry might be useful to determine the maximal safe degree and duration of globe retraction. The current literature reports no orbital complications despite operative times of up to 4 hours ${ }^{35}$ and concerns about the risk of cerebrospinal fluid leak. However, Dallan et al. suggested that the orbit contents may act as a natural seal, minimizing the risk of a postoperative CSF leak. ${ }^{13}$ Finally, other concerns include the cosmetic effect associated with the loss of orbital bone, and the risk of postoperative enophthalmos and diplopia. Although initial clinical experience appears encouraging, ${ }^{35}$ surgical series are necessary to assess the burden of those potential complications.

This anatomical study on the feasibility of the superior eyelid endoscopic transorbital route is promising, with its contribution to understanding the anatomy and the capabilities of this relatively novel approach, but limited in clinical utility. Limits of its clinical utility should be considered as a separate issue; these deserve additional studies that are currently underway.

\section{Conclusions}

The purely endoscopic superior eyelid transorbital approach affords good visualization and allows surgical manipulation of structures in the anterior and middle cranial fossae. In particular, we demonstrated that lateral orbital corridors to the superior and inferior orbital fissures permitted exposure of the most lateral portion of the middle or the anterior cranial fossa. Further bone removal medially to the superior and inferior orbital fissures provides access to the opticocarotid region. Better surgical exposure appeared more consistent with lateral approaches as compared with the middle corridor to the opticocarotid region. Surgical series are needed to establish the clinical value of these approaches to better determine their place in the armamentarium of modern skull base surgery.

\section{References}

1. Adawi MM, Abdelbaky AM: Validity of the lateral supraorbital approach as a minimally invasive corridor for orbital lesions. World Neurosurg 84:766-771, 2015

2. AlQahtani A, Padoan G, Segnini G, Lepera D, Fortunato S, Dallan I, et al: Transorbital transnasal endoscopic combined approach to the anterior and middle skull base: a laboratory investigation. Acta Otorhinolaryngol Ital 35:173-179, 2015

3. Anderson RL, Linberg JV: Transorbital approach to decompression in Graves' disease. Arch Ophthalmol 99:120-124, 1981

4. Banu MA, Mehta A, Ottenhausen M, Fraser JF, Patel KS, Szentirmai O, et al: Endoscope-assisted endonasal versus supraorbital keyhole resection of olfactory groove meningiomas: comparison and combination of 2 minimally invasive approaches. J Neurosurg 124:605-620, 2016

5. Bir SC, Konar SK, Maiti TK, Thakur JD, Guthikonda B, Nanda A: Utility of neuronavigation in intracranial meningioma resection: a single-center retrospective study. World Neurosurg 90:546-555, 555.e1, 2016
6. Bly RA, Ramakrishna R, Ferreira M, Moe KS: Lateral transorbital neuroendoscopic approach to the lateral cavernous sinus. J Neurol Surg B Skull Base 75:11-17, 2014

7. Carlson ML, Copeland WR III, Driscoll CL, Link MJ, Haynes DS, Thompson RC, et al: Temporal bone encephalocele and cerebrospinal fluid fistula repair utilizing the middle cranial fossa or combined mastoid-middle cranial fossa approach. J Neurosurg 119:1314-1322, 2013

8. Cavalcanti DD, García-González U, Agrawal A, Crawford NR, Tavares PL, Spetzler RF, et al: Quantitative anatomic study of the transciliary supraorbital approach: benefits of additional orbital osteotomy? Neurosurgery 66 (6 Suppl Operative):205-210, 2010

9. Chen HI, Bohman LE, Loevner LA, Lucas TH: Transorbital endoscopic amygdalohippocampectomy: a feasibility investigation. J Neurosurg 120:1428-1436, 2014

10. Cheng CM, Noguchi A, Dogan A, Anderson GJ, Hsu FP, McMenomey SO, et al: Quantitative verification of the keyhole concept: a comparison of area of exposure in the parasellar region via supraorbital keyhole, frontotemporal pterional, and supraorbital approaches. J Neurosurg 118:264-269, 2013

11. Chotai S, Kshettry VR, Petrak A, Ammirati M: Lateral transzygomatic middle fossa approach and its extensions: surgical technique and 3D anatomy. Clin Neurol Neurosurg 130:33-41, 2015

12. D’Ambrosio AL, Sughrue ME, Mocco J, Mack WJ, King RG, Agarwal S, et al: A modified transorbital baboon model of reperfused stroke. Methods Enzymol 386:60-73, 2004

13. Dallan I, Castelnuovo P, Locatelli D, Turri-Zanoni M, AlQahtani A, Battaglia P, et al: Multiportal combined transorbital transnasal endoscopic approach for the management of selected skull base lesions: preliminary experience. World Neurosurg 84:97-107, 2015

14. Dallan I, Di Somma A, Prats-Galino A, Solari D, Alobid I, Turri-Zanoni M, et al: Endoscopic transorbital route to the cavernous sinus through the meningo-orbital band: a descriptive anatomical study. J Neurosurg [epub ahead of print November 18, 2016. DOI: 10.3171/2016.8.JNS16465]

15. Dallan I, Locatelli D, Turri-Zanoni M, Battaglia P, Lepera D, Galante N, et al: Transorbital endoscopic assisted resection of a superior orbital fissure cavernous haemangioma: a technical case report. Eur Arch Otorhinolaryngol 272:3851-3856, 2015

16. Dashti SR, Fiorella D, Spetzler RF, Albuquerque FC, McDougall CG: Transorbital endovascular embolization of dural carotid-cavernous fistula: access to cavernous sinus through direct puncture: case examples and technical report. Neurosurgery 68 (1 Suppl Operative):75-83, 2011

17. de la Torre JC, Surgeon JW: Dexamethasone and DMSO in experimental transorbital cerebral infarction. Stroke 7:577583,1976

18. Delashaw JB Jr, Tedeschi H, Rhoton AL: Modified supraorbital craniotomy: technical note. Neurosurgery 30:954-956, 1992

19. Di Somma A, Cavallo LM, de Notaris M, Solari D, Topczewski TE, Bernal-Sprekelsen M, et al: Endoscopic endonasal medial-to-lateral and transorbital lateral-to-medial optic nerve decompression: an anatomical study with surgical implications. J Neurosurg [epub ahead of print October 28, 2016. DOI: 10.3171/2016.8.JNS16566]

20. Dolenc VV: Frontotemporal epidural approach to trigeminal neurinomas. Acta Neurochir (Wien) 130:55-65, 1994

21. Erturk M, Kayalioglu G, Govsa F, Varol T, Ozgur T: The cranio-orbital foramen, the groove on the lateral wall of the human orbit, and the orbital branch of the middle meningeal artery. Clin Anat 18:10-14, 2005

22. Fatemi N, Dusick JR, de Paiva Neto MA, Malkasian D, Kelly DF: Endonasal versus supraorbital keyhole removal of cra- 
niopharyngiomas and tuberculum sellae meningiomas. Neurosurgery 64 (5 Suppl 2):269-286, 2009

23. Fiamberti AM: [The original method of transorbital leukotomy.] Med Hyg (Geneve) 10:195, 1952 (Fr)

24. Freeman W: Transorbital leucotomy. Lancet 2:371-373, 1948

25. Gardner PA, Kassam AB, Thomas A, Snyderman CH, Carrau RL, Mintz AH, et al: Endoscopic endonasal resection of anterior cranial base meningiomas. Neurosurgery 63:36-54, 2008

26. Hakuba A, Tanaka K, Suzuki T, Nishimura S: A combined orbitozygomatic infratemporal epidural and subdural approach for lesions involving the entire cavernous sinus. J Neurosurg 71:699-704, 1989

27. Huang J, Mocco J, Choudhri TF, Poisik A, Popilskis SJ, Emerson R, et al: A modified transorbital baboon model of reperfused stroke. Stroke 31:3054-3063, 2000

28. Hudgins WR, Garcia JH: Transorbital approach to the middle cerebral artery of the squirrel monkey: a technique for experimental cerebral infarction applicable to ultrastructural studies. Stroke 1:107-111, 1970

29. Kazdal H, Kanat A, Findik H, Sen A, Ozdemir B, Batcik OE, et al: Transorbital ultrasonographic measurement of optic nerve sheath diameter for intracranial midline shift in patients with head trauma. World Neurosurg 85:292-297, 2016

30. Koppe M, Gleizal A, Orset E, Bachelet JT, Jouanneau E, Rougeot A: Superior eyelid crease approach for transobital neuroendoscopic surgery of the anterior cranial fossa. J Craniofac Surg 24:1616-1621, 2013

31. Laufer I, Anand VK, Schwartz TH: Endoscopic, endonasal extended transsphenoidal, transplanum transtuberculum approach for resection of suprasellar lesions. J Neurosurg 106:400-406, 2007

32. Lim JH, Sardesai MG, Ferreira M Jr, Moe KS: Transorbital neuroendoscopic management of sinogenic complications involving the frontal sinus, orbit, and anterior cranial fossa. J Neurol Surg B Skull Base 73:394-400, 2012

33. Linberg JV, Anderson RL: Transorbital decompression. Indications and results. Arch Ophthalmol 99:113-119, 1981

34. Madrazo Navarro I, Garcia Renteria JA, Rosas Peralta VH, Dei Castilli MA: Transorbital ventricular puncture for emergency ventricular decompression. Technical note. J Neurosurg 54:273-274, 1981

35. Moe KS, Bergeron CM, Ellenbogen RG: Transorbital neuroendoscopic surgery. Neurosurgery 67 (3 Suppl Operative):ons16-ons28, 2010

36. Nonaka Y, Fukushima T, Watanabe K, Sakai J, Friedman AH, Zomorodi AR: Middle infratemporal fossa less invasive approach for radical resection of parapharyngeal tumors: surgical microanatomy and clinical application. Neurosurg Rev 39:87-97, 2016

37. O'Brien MD, Waltz AG: Transorbital approach for occluding the middle cerebral artery without craniectomy. Stroke 4:201-206, 1973

38. Parkinson D: Direct obliteration of carotid-cavernous fistulas. J Neurosurg 66:948, 1987

39. Ramakrishna R, Kim LJ, Bly RA, Moe K, Ferreira M Jr: Transorbital neuroendoscopic surgery for the treatment of skull base lesions. J Clin Neurosci 24:99-104, 2016
40. Robison RA, Taghva A, Liu CY, Apuzzo ML: Surgery of the mind, mood, and conscious state: an idea in evolution. World Neurosurg 80:S2-S26, 2013

41. Rowed DW, Kassel EE, Lewis AJ: Transorbital intracavernous needle biopsy in painful ophthalmoplegia. Case report. J Neurosurg 62:776-780, 1985

42. Shintani A, Zervas NT, Kuwayama A, Pallotta J, Spark R: Transorbital pituitary stalk section in primates. J Neurosurg 37:601-605, 1972

43. Steiger HJ, Schmid-Elsaesser R, Stummer W, Uhl E: Transorbital keyhole approach to anterior communicating artery aneurysms. Neurosurgery 48:347-352, 2001

44. Stippler M, Gardner PA, Snyderman CH, Carrau RL, Prevedello DM, Kassam AB: Endoscopic endonasal approach for clival chordomas. Neurosurgery 64:268-278, 2009

45. Topcuoglu MA, Arsava EM, Bas DF, Kozak HH: Transorbital ultrasonographic measurement of optic nerve sheath diameter in brain death. J Neuroimaging 25:906-909, 2015

46. Tripathi M, Deo RC, Suri A, Srivastav V, Baby B, Kumar S, et al: Quantitative analysis of the Kawase versus the modified Dolenc-Kawase approach for middle cranial fossa lesions with variable anteroposterior extension. J Neurosurg 123:14-22, 2015

47. Tubbs RS, Loukas M, Shoja MM, Cohen-Gadol AA: Emergency transorbital ventricular puncture: refinement of external landmarks. J Neurosurg 111:1191-1192, 2009

48. Wada T, Toyota M: Transorbital brain-ventricle puncture or a new method for pneumoventriculography. Tohoku J Exp Med 54:223-226, 1951

49. Wilson SR, Schauer B, Price DD: Transorbital ventricular decompression in an acutely decompensated hydrocephalic ED patient. Am J Emerg Med 25:208-210, 2007

\section{Disclosures}

The authors report no conflict of interest concerning the materials or methods used in this study or the findings specified in this paper.

\section{Author Contributions}

Conception and design: Andaluz, Di Somma, Cavallo, Cappabianca. Acquisition of data: Andaluz, Di Somma, Cavallo, de Notaris, Solari, Zimmer, Keller, Prats-Galino, Cappabianca. Analysis and interpretation of data: Andaluz, Di Somma, Cavallo, de Notaris, Dallan, Solari, Zimmer, Zuccarello, Cappabianca. Drafting the article: Andaluz, Di Somma, Cavallo, de Notaris, Dallan, Solari, Zimmer, Zuccarello. Critically revising the article: Andaluz, Di Somma, Cavallo, de Notaris, Dallan, Solari, Zimmer, Keller, Prats-Galino, Cappabianca. Reviewed submitted version of manuscript: all authors.

\section{Correspondence}

Norberto Andaluz, c/o Medical Communications, Departments of Neurosurgery, University of Cincinnati College of Medicine, ML 0515, Cincinnati, OH 45267-0515. email: mkemper@ mayfieldclinic.com . 